CASE v and sin. broad on left cheek (Fig. 4) Exposed piecemeal to the snow for five seconds on March 16th. A reaction occurred next day, followed by a marked improve ment, and the lesion became less prominent and paler. An application of forty seconds was given on April 15th, and as result the pigmentation and much of the hair was destroyed.

Subsequent applications were given on July 6 th of forty seconds, August 24th of sixty seconds, and October 12th of twenty seconds. The condition on November $23 \mathrm{rd}$ is as shown in the illustration (Fig. 5). The lesion has been replaced by supple, little disfiguring scar, and almost all the pigmentation has gone. A certain amount of thickening still persists towards the lower edge. The treatment of the case is not yet completed, and further applications will be given to remove the slight thickening and to destroy the remaining hairs.

\section{Lupus Vulgaris.}

A number of cases of lupus vulgaris have been subjected to this treatment, and where the lesions are superficial in type I have found it to be of definite ralue, but in deep. seated lesions it seems to be less effective and penetrating than Finsen light.

Lupus Erythematosus.

I have treated several cases of lupus erythematosus of the chronic discoid variety by this method, and though they have all benefited by it, and none of them have been aggravated, I am not convinced that it is as good a local remedy for this disease as zinc ionization. The following is an illustrative case :

R. S., aged 49, with a patch of lupus erythematosus on the bridge of the nose extending towards the left cheek and another patch in front of the left ear. It was exposed to the snow piecemeal for five seconds on July. 2lst. A sharp reaction piecemeal for five seconds on July. 2lst. A sharp reaction occurred, which on subsiding left considerable improvement. 23rd a great improvement was noted : the greater part of the nasal lesion had healed with slight scarring, and the patient said that the affected skin felt much more comfortable.

Rodent Ulcers.

Carbon dioxide snow is capable of destroying rodent ulcers provided they are superficial and do not involve deep structures. In a case of such a lesion situated on the cheek, an excellent result was obtained (Fjgs. 6 and 7), but in this affection the treatment does not seem to me to be much better than the careful application of the actual cautery, and where the lesions penetrate deeply it is of less value than radium.

Sufficient has been said to indicate the therapeutic value and possibilities of this new agent. In conclusion I must take this opportunity of thanking my clinical assistant, Dr. Dyce Fraser, for the valuable help he has given me in the treatment of these cases.

REFERENCE.

1 Berliner klinische Wochenschrift.

\section{SOME RESULTS OBTAINED FROM THE LOCAL APPLICATION OF SOLID CARBON DIOXIDE.}

\section{By EDWARD REGINALD MORTON, M.D.ToR.,} F.R.C.S.EDIN.,

LECTORER ON RADIOLOGY, WEST LONDON POST-GRADUATE COLLEGE.

THERE is some difference of opinion as to the relative value of solid carbon dioxide and liquid air in the treat. ment of naevi and other cutaneous lesions, and while I do not dispute the claims on behalf of the latter agent made by those who have had more experience with it than I have, yet I venture to say that the more they use carbon dioxide, properly compressed into a hard, tirm crayon, the more they will like it, and even prefer it to any other agent.

Liquid air certainly possesses the quality of extreme cold far beyond that of solid carbon dioxide or anything else at present available; but, in my opinion, the tempera ture of solid carbon dioxide, equivalent to $142^{\circ}$ of frost, is low enough for anything required in therapentics, and yet not so low but that it is perfectly manageable and easy to control. In addition to all this, carbon dioxide can be kept in the house ready for use at any time, and no more need be taken from the cylinder than is necessary for the case in hand. There is no way of storing liquid air, and when any is wanted it is necessary to give some hours' notice, and it must be used within a very few hours of its preparation. These conditions are not always con. venient, and it is not given to every one to reside in the near neighbourhood of a laboratory where liquid air is prepared. A cylinder of the liquefied carbon dioxide (from which the solid crayon is prepared) can be sent anywhere, to be used at convenience, and now that small cylinders of $\mathrm{CO}_{2}$ are being used by motorists for inflating tyres it is more easy than ever to obtain and use this valuable agent.

The mode of preparing and using solid carbon dioxide I have more or less fally described in another paper, ${ }^{1}$ and in this article $I$ propose to give the results $I$ bave obtained in a series of 123 cases. This number does r ot include all the cases I have treated-the total would be about 200-as at times it is very difficult to get all the cases written up. It takes no account of a number that I have treated at the West London Hospital, through the kindness of..Dr. Abraham, nor does it include those that have come to me in the course of my private practice. Were all these included, the effect.would be to make the general result more favourable than it is. It does include practically all the cases I have treated from the beginging, when I had everything to learn, and no past experience to guide me clear of pitfalls-cases where two or more applications were necessary, that now would be treated successfully with one. The faults were found to be-due, for the most part, to an improper degree of pressure, and, to a less extent, to errors in the time of the application. If the pressure is too light, the result is incomplete; if too heavy, the reaction is needlessly severe, and some necrosis may possibly. follow.

The 123 cases were made up as follows:

$$
\begin{array}{lccccr}
\text { Naevi } \ldots & \ldots & \ldots & \ldots & \ldots & 105 \\
\text { Common warts } & \ldots & \ldots & \ldots & \ldots & 12 \\
\text { Lupus vulgaris } & \ldots & \ldots & \ldots & \ldots & 1 \\
\text { Lupus erythematosus } & \ldots & \ldots & \ldots & 1 \\
\text { Moles } \ldots & \ldots & \ldots & \ldots & \ldots & 4 \\
\end{array}
$$

Lupus.

The two cases of lupus were sent to me in the hospital for trial by my colleague, Dr. Sequeira, before be took up the method himself. The case of lupus vulgaris was not very suitable; the patch was near the bend of the elbow, where it was difficult to make firm pressure, and the great amount of movement incidental to the part made healing difficult. It was not successful. No one, of course, would draw any definite conclusions from this, and I may say that since then I have treated some patches on the inner side of a child's foot with, so far as it is possible to judge at present, very satisfactory results, but it is too soon to draw any conclusions as to the efficacy of carbon dioxide in the treatment of this disease. The case of lopus erythematosus was a fairly extensive one. The disease affected the face, back of the pelvis, and both anterior tibial regions. There was a very marked improvement after the reaction from each application had subsided. This, however, is no more than can be said for a number of other methods that are in more or lees regular use for the treatment of this troublesome disease. Here again further investigation is called for before we claim too much or too little.

Moles.

Only 4 cases were treated, but the results have been highly satisfactory; 3 were cured, leaving a very small scar that is almost imperceptible, the result in each case being highly gratifying to the patient as well as to myself. The fourth case was improved but it was one of unusual difficulty. It was, in fact, an exaggeration and pigmenta. tion of a little boy's left eyebrow. Its size and hairy growth were such as one would find on a full-grown man. The idea of the treatment was to destroy a part only in order to bring it to a proper size and shape. It is noteworthy that hair is removed by the application, but it is too soon to say if the epilation will be permanent.

Warts.

The treatment here is very simple, and it is not necessary to time the application; in fact, the attempt to judge the proper dose by timing is doomed to failure. The chief disturbing factor is the very poor conducting properties of 
the growth. The crayon of solid $\mathrm{CO}_{2}$ is trimmed to a diameter corresponding to that of the growth. The application is made with firm pressure, and continued until a narrow ring of the healthy tissue around the base of the growth is white and frozien by conduction from the centre. Properly carried out in this way there should never be a failure in dealing with a common wart. In the reaction that ensues a blister is formed under the base of the wart, causing it to be thrown off. Twelve cases were treated in the series mader consideration; 9 were completely cured, 2 are still under treatment, and 1 ceased attending. There was no reason to think that these last would not be equaliy successful under further treatment.

\section{Naevi.}

The 105 cases presented 129 naevi for treatment, which were made up as follows:

\begin{tabular}{|c|c|c|c|c|}
\hline Capillary ... & ... & $\ldots$ & ... & $\ldots$ \\
\hline Cavernous & $\ldots$ & & ... & $\ldots$ \\
\hline Capillary and cav & vernou & (mixed) & ... & $\ldots$ \\
\hline Stellate $\ldots$ & $\ldots$ & $\ldots$ & ... & $\ldots$ \\
\hline Lymphatic & $\ldots$ & ... & $\ldots$ & $\ldots$ \\
\hline Port-wine marks & $\ldots$ & ... & ... & $\cdots$ \\
\hline $\begin{array}{l}\text { tribution: } \\
\text { Head and neck }\end{array}$ & & & & \\
\hline & ... & $\cdots$ & ... & $\cdots$ \\
\hline $\begin{array}{ll}\text { Arms } & \ldots \\
\text { Thorax } & \ldots\end{array}$ & $\cdots$ & $\cdots$ & $\cdots$ & $\cdots$ \\
\hline $\begin{array}{l}\text { Thorax ... } \\
\text { Abdomen ... }\end{array}$ & $\cdots$ & $\cdots$ & $\cdots$ & ... \\
\hline $\begin{array}{l}\text { Abdomen ... } \\
\text { Pelvis } \quad . .\end{array}$ & $\cdots$ & $\cdots$ & $\cdots$ & $\cdots$ \\
\hline Perineum and ge & nitals & $\ldots$ & $\begin{array}{l}\cdots \\
\ldots\end{array}$ & $\ldots$ \\
\hline Legs $\quad \ldots$ & $\ldots$ & $\ldots$ & $\ldots$ & $\ldots$ \\
\hline
\end{tabular}

Of the 85 capillary naevi, no less than 74 were cured by a single application of solid $\mathrm{CO}_{2}$ lasting, on an average, forty seconds; 6 cases had two, 2 had three, and 2 had four applications; while 1 case was incompletely cured after three attempts and was finally finished off by electrolysis.

Of the 32 cavernous naevi, 20 were cured by one application, 4 had two, and 2 had three applications; 6 cases were incompletely cured or not benefited, and finally dealt with by electrolysis.

In all cases in which the capillary and cavernous varieties were coexistent the capillary part was treated by $\mathrm{CO}_{2}$ and the rest by electrolysis. Of the whole series, 12 had finally to be dealt with by electrolysis. The stellate naevus and the two lymphatic naevi were all cured by a single application of $\mathrm{CO}_{3}$

At the time of writing, the cases of "port-wine mark" are still under treatment. These cases require much time whatever the mode of treatment employed, but I am convinced that in $\mathrm{CO}_{2}$ we have a remedy better than any hitherto known, except perhaps radium, as I have seen equally good results from both. All the cases I have treated with $\mathrm{CO}_{2}$ are doing exceedingly well, and the outlook is very hopeful. It is noteworthy that in treating cases of this kind the first application seems to have little or no influence in reducing the depth of colour, even after waiting three weeks. After the second application the effect is very marked, and may be sufficient.

It will be seen from the above results that, taking capillary naevi as they come, no less than 87 per cent. have been cured by a single application, and I venture to say that with greater experience an even higher percentage would be obtained were I starting a similar series again. As might be expected, the results in treating cavernous naevi were not so good, but even here the proportion cured by a single application was as high as 63 per cent.

Higher percentages of cures are, of course, possible and obtained by other methods, such as electrolysis and the cautery, bat it must be remembered that with these a general anaesthetic is always necessary. No anaesthetic local or general, is ever necessary with carbon dioxide, as the application is practically painless and of only a few seconds' duration. I have had children who never cried or moved during the application; this is, of course, exceptional, but it does show that the process cannot be a very severe one.

\section{THE CLINICAL ESTIMATION OF "ACIDOSIS."}

By A. E. BARNES, M.B., M.R.C.P.,

MEDICAL REGISTRAR, ROYAI INEIRMARY, SHEFFIELD; MEDICAL TOTOR, UNIVERSITY OF SHEFFIELD ; LATE RESEARCH SCHOLAR, BRITISH MEDICAL ASSOCIATION.

THE subject of acid intoxication is becoming daily of greater importance, it being more generally recognized as a terminal condition in a large number of diseases. Although it usually proves fatal, yet the occasional brilliant success which follows properly applied therapentic measures must render welcome any means by which the condition may be recognized before it has reached a stage bejond hope of recovery. It seems desirable, therefore, to record some of the routine methods which have been made use of in the work of the Practical Medicine Laboratory of the University of Sheffield during recent months, from which results of considerable interest have been obtained. No originality is claimed for the methods here described. It is well recognized that acidosis may exist for years with. out any marked effect upon the general health, but, whilst at any time the acidosis may increase to such an extent as to become a positive danger and demand urgent treatment, yet the means at our disposal for knowing when that danger is imminent are as yet incomplete.

To remedy this defect it is necessary that a large number of cases should be examined and followed up for prolonged periods. It is therefore essential that such methods of examination should be used as.will, whilst giving a good general idea of the state of metabolism, not be too complicated for general clinioal use. The first requirement is a method which will show approximately the amount of organic acid in the urine. It has been assumed that in diabetes the $\beta$ oxybutyric acid is the factor which requires measurement, and various methods have been devised to do this. All of them, however, are either difficult to carry out or require expensive apparatus. The usual method of estimating the quantity from the difference between the values obtained for dex. trose by titration and polarization respectively involves not only expensive apparatus, but the assumption that all the difference is due to the above acid-an assumption which seems somewhat unsafe in view of the fact that many cases of severe diabetes give a definite reaction for laevulose when tested by Seliwanoff's method. The other methods of extraction by ether are very tedious, and even that with the best apparatus (Lind's) is stated to require seven hours for complete extraction.

To obviate these difficulties we have used a modification of Folin's method for determining the total organic acidity of the urine. In this method all the organic acids are estimated together, including, therefore, uric and hippuric as well as the fatty acids. The latter, however, are so small in quantity that they may be neglected.

\section{Method.}

1. Take $20 \mathrm{c.cm}$. of urine. Dilute with water and add some crystals of neutral potassium oxalate and a few drops of alco holic solution of phenolphthalein. Titrate with decinormal caustic soda solution until a definite red tinge appears. The number representing the total acidity is obtained as follows:

C.cm. of $\frac{\mathrm{N}}{\mathrm{I0}}$ caustic soda solution used

20 (c.cm. of urine)

The total acidity for twenty-four hours thus expressed in units of decinormal soda is due to acid salts and to organic acids not combined with alkalis or ammonia.

2. The titration is now carried a stage further by adding to the same urine mixture $2 \mathrm{c.cm}$. of previously neutralized commercial formalin. (The neutralization is easily done by adding phenolphthalein followed by dilute alkali until a pink colonr peper In a few seconds the pink coloration of the mixture disappears. This isdue to the fact that the ammonia present in the urine in combination with acids has united in a condensation reaction with the formaldehyde as hexamethylenetetramine. Thus the acid which was previously combined with this ammonia base has been set free, causing the disappearance of the pink colour. Further titration is now carried out with the same decinormal caustic soda solution until the pink colour reappears. The number of cubic centimetres of decinormat ca of the urine which has been neutralized by the ammonia, and thisis the factor which we require to determine the organic acids; thisis the factor which we require to determine the organic acids; metre of decinormal caustic soda solution used in this second 